\title{
Uso de teléfonos móviles/pulsadores en el aprendizaje interactivo de la Microbiología
}

\author{
Beatriz Santos Romero; Margarita Díaz Martínez
}

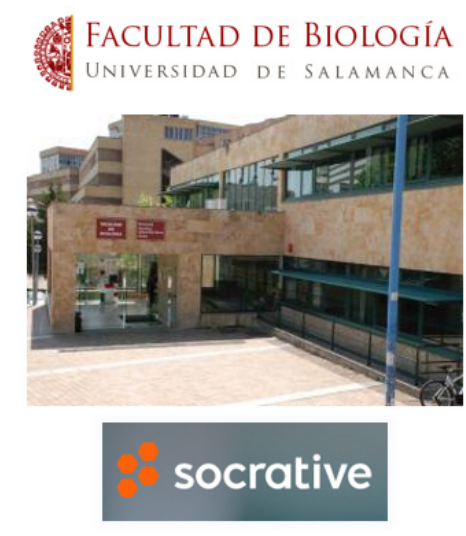

ARA MEJORAR EL APRENDIZAJE DE LA MiCROBIOloGía en el alumnado se persiguen los siguientes objetivos:

1. Incrementar la atención, implicación y motivación del alumno durante las clases.

2. Valorar el grado de aprendizaje de los alumnos en las clases de forma directa.

3. Detectar aquellos aspectos de la asignatura en los que haya que reforzar su explicación.

4. Posibilitar la adquisición de competencias transversales: trabajo en equipo, toma de decisiones, capacidad de resumir información, etc.

Para el desarrollo de estos objetivos se utiliza una metodología interactiva en clase basada en aplicaciones de teléfonos móviles o pulsadores. Concretamente, se utilizan materiales elaborados por las profesoras en la plataforma on-line Socrative.

El desarrollo de esta práctica comienza explicando en clase cómo usar Socrative y comprobando que todo funciona correctamente. Una vez se ha entendido su funcionamiento, se aplica la herramienta a lo largo del curso. 
La dinámica es la siguiente:

- El profesor elabora un cuestionario sobre el tema que se va a tratar y se imprime.

- Los alumnos se disponen en grupos de 5-6 y se reparte un cuestionario a cada grupo, otorgándoles un tiempo determinado para rellenarlo (5-10 minutos).

- Cada equipo elige un nombre y un portavoz y se conecta a Socrative.

- El profesor lanza el cuestionario de distintas formas:

- Race: se rellena el cuestionario completo on-line. Se puede hacer en forma de carrera dando premios al mejor grupo.

- Teacher paced: se contesta a las preguntas de una en una viendo las respuestas en la pantalla y comentándolas.

- Al final se genera un informe en formato Excel para su posterior análisis por el profesor.

Se realizan dos tipos de actividades:

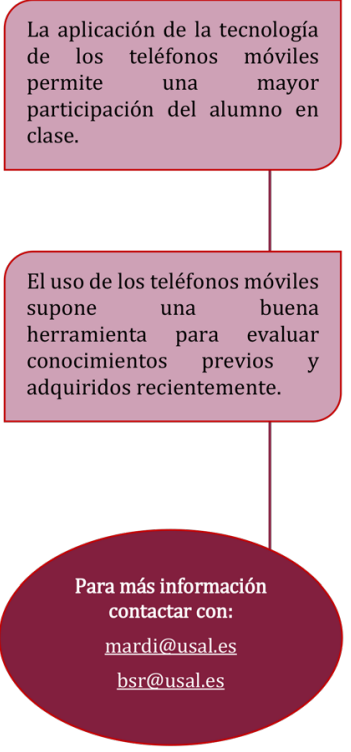

1. Sobre los conocimientos previos: para temas que se imparten en diferentes asignaturas para evitar repetir contenidos. Se pone de manifiesto lo que los alumnos ya conocen y lo que hay que explicar en más profundidad. Permite introducir y centrar el tema, no repetir conceptos, asegurarse de que conocen los conceptos previos necesarios para abordar el tema. Resultados: detectar aquellos aspectos que requerirían de una mayor atención y aquellos en los que habría que incidir menos.

2. Sobre los conocimientos adquiridos: se desarrollará especialmente en aquellos temas de difícil aprendizaje, para comprobar si los alumnos han entendido los contenidos explicados. Se realizará al finalizar el tema. Resultados: valorar el grado de aprendizaje de manera directa.

La mayor innovación es la incorporación de TIC en el desarrollo de la docencia a través del uso de teléfonos móviles. La conexión en el aula se realiza on-line, no siendo necesario descargarse la aplicación.

Con esta actividad se ha podido constatar una mayor participación del estudiante en clase mejorando su atención, implicación y motivación.

De esta forma, se trabajan diferentes competencias transversales como: el trabajo en equipo, la toma de decisiones, la capacidad de resumir... 